\title{
Knowing Me is the Key: Implications of Anticipatory Psychological Contract for Millennials' Retention
}

\author{
Nada Zupan \\ Katarina Katja Mihelič \\ Darija Aleksić
}

\section{Author Copy}

To be published as a chapter in Coetzee, Melinde, Potgieter, Ingrid L., Ferreira, Nadia (Eds.).

Psychology of Retention: Theory, Research, Practice. Springer, doi: 10.1007/978-3-319-989204_15 


\title{
Chapter 15 \\ Knowing Me is the Key: Implications of Anticipatory Psychological Contract for Millennials' Retention
}

Nada Zupan, Katarina Katja Mihelič, and Darija Aleksić

Faculty of Economics, University of Ljubljana, Slovenia

nada.zupan@ef.uni-lj.si

\begin{abstract}
Millennial talents are an important source of competitive advantage in an increasingly digitalized and globalized business environment. However, many employers report challenges related to attracting, managing and especially retaining young talents. Often, individual preferences and needs are not known and(or) sufficiently considered, which creates tensions and increases the risk of losing young talents. We explore Millennials' employment expectations with the anticipatory psychological contract in two under investigated contexts - Central and Eastern Europe and East Asia. A quantitative research design is used to analyse the features of anticipatory psychological contract, employing samples of undergraduate business students. Findings reveal that Millennials prefer balanced types of anticipatory psychological contract for both employee and employer obligations, followed by relational and transactional types. The analysis uncovered certain regional differences as well. In addition, potential psychological contract breach situations are identified for a Slovenian sample when comparing students' and employers' expectations. Based on these insights we propose relevant retention strategies and practices for young talent retention.
\end{abstract}

Keywords: anticipatory psychological contracts, employment expectations, Millennials, psychological contract breach, talent retention, Central and Eastern Europe, East Asia 


\section{Introduction}

How to keep employees engaged and interested in staying in the company has become a pervasive issue for HR professionals, managers, and leaders. Specifically, in recent years, interest has grown in terms of how to retain the youngest employees, often referred to as Millennials. These young talents with unique values, beliefs and expectations, are changing existing HR practices. Many suggest that due to their distinct characteristics Millennials need a special consideration with regard to talent management models used by their employers (e.g. McCracken, Currie \& Harrison, 2016; Festing \& Schäfer, 2014). Stereotypically, Millennials are characterized as disloyal, difficult to work with, entitled, and individualistic. Unlike previous generations, they put much less emphasis on work and more on hobbies and leisure time. Born in times of increased globalization and digital transformation, they are not afraid of changes. They have witnessed that job stability and working for a single employer in the entire working life are becoming outdated. They appreciate varied and challenging tasks and they build their career based on their personal development and not loyalty to an employer. We see these characterizations in popular press and everyday discussions. Nevertheless, academic research about Millennials at work both confirms and disputes some of these claims (e.g. Twenge, 2010; Cogin, 2012; Becton, Walker \& JonesFarmer, 2014; Kuron, Lyons, Schweitzer \& Ng, 2015; Stewart, Oliver, Cravens, \& Oishi; 2017). This confusion about who the Millennials are and what they want is calling for further and more theory-based research.

Millennials' expectations regarding employment can be approached with a psychological contract (PC) perspective, which has proven to be a useful concept for researching talent management (Gallardo-Gallardo, Nijs, Dries \& Gallo, 2015), and particularly talent retention (Festing \& Schäfer, 2014; D’Amato \& Herzfeld, 2008). A PC is usually referred to as employee and employer perceptions regarding their mutual employment obligations (Rousseau, 1995), they are subjective and implicit. Many studies show that a breach of the PCs leads to lower employee satisfaction and commitment as well as higher turnover intentions (Zhao, Wayne, Glibkowski, \& Bravo, 2007). Therefore, it is important to study PCs to understand and manage employee expectations regarding the employment relationship. In addition, anticipatory psychological contracts (APC), which refer to individuals' pre-employment beliefs about expected employee and future employer obligations, provide useful insights into young talents' expectations (e.g. De Vos, De Stobbeleir, \& Meganck, 2009). Although they are often based on incomplete information (Sherman \& Morely, 2015) and naïve (Dulac et al., 2006), entrants into labour market use APCs to evaluate relationship with prospective employers (Sherman \& Morley, 2015). As such, APCs have important implications for talent management, especially for recruitment and retention.

Thus far, most of what is known about Millennials comes from studies conducted in developed and mostly Western countries, while researchers rarely address other geographical contexts. In addition, extant studies on APC focus mostly on what prospective employees expect and the employers' perspective has been largely neglected. The main objective of this chapter is to deepen our understanding about expectations that Millennials have about their future work and employment relationship and how those might affect their retention. Thus, we intend to complement the existing literature by addressing the following research questions: 1) What are the features of Millennials' APC in transitional countries in Central and Eastern Europe (CEE) and 
East Asia (EA)?, 2) What are the differences among Millennials, in regards to APC, employment preferences, demographics and geographical location?, and 3) What are the potential risks for psychological contract breach and increased turnover intentions once Millennials get their first employment? In order to answer these questions, a quantitative research design was used. The data for the first study were collected from Millennials in two CEE (Slovenia and Poland) and EA countries (China and South Korea), addressing the first two research questions. Additionally, employers' data were collected in Slovenia on their perception of PCs for Millennials for the second study to answer the third research question.

In what follows, we describe the theoretical background regarding Millennials at work and retention challenges faced by employers. The last theoretical part focuses on establishing the link between PC, PC breach and turnover intensions. Next, we present results of both studies, followed by a discussion and practical implications for retention management.

\section{Theoretical background}

\section{Millennials and work}

Because Millennials are changing the nature of relationships and ways of working in organizations, academic interest in their characteristics has grown over the years. Unlike previous generations, Millennials have embraced the "work to live" philosophy of life (Johnson \& Johnson, 2010), as evident from a lower work centrality (Smola \& Sutton, 2002; Twenge, Campbell, Hoffman, \& Lance, 2010) and a desire for more leisure time and work-life balance (Kuron et al., 2015). Overall, research finds that Millennials are more extrinsically motivated (Twenge et al., 2010). A recent empirical study confirms that they perceive as the most important extrinsic work values, such as work-life balance, salary, job security, but intrinsic values such as achievement, interesting work and advancement are also important to them (Kuron et al., 2015). Especially learning, development and advancement have been identified among top work values for Millennials (Lyons \& Kuron, 2014; Zupan, Kaše, Rašković, Yao, \& Wang, 2015), but it seems their wish to enhance professional skills through training and mentoring is often linked to a desire to be flexible and remain marketable (Holden \& Harte, 2004; Cennamo \& Gardner, 2008). While they are willing to invest effort in their work and demonstrate excellent performance, at the same time they want much in return, and quickly (Winter \& Jackson, 2016). Another important thing they look for in a potential employer is a meaningful and fulfilling job ( $\mathrm{Ng}$, Schweitzer, \& Lyons, 2010).

According to recent research, young Millennials prefer organizations that stress a socially responsible culture and a work environment characterized by collegiality (Kuron et al., 2015). They want to get involved in decision-making (Luscombe, Lewis, \& Biggs, 2013). Millennials have different communication patterns and feel most comfortable using text-based or computermediated communication (Pearson, Carmon, Tobola, \& Fowler, 2010). They are self-centred and stubborn and want to climb the hierarchical ladder quickly. In fact, seeking opportunities for fast career advancement is Millennials' high priority thus confirming that they are ambitious ( $\mathrm{Ng}$ et al., 2010). They also expect investments of their employers into career management (Kong, Wang $\& \mathrm{Fu}, 2015)$.

In terms of relationships at work, they want a greater level of support from managers $(\mathrm{Ng}$ et al., 2010), the development and maintenance of high-quality work relationships (Kong et al., 2015), they appreciate feedback (Graen \& Schiemann, 2013) and praise (Shaw \& Fairhurst, 2008). 
They do not want to be micromanaged (Broadbridge, Maxwell \& Ogden, 2007), although they may seek detailed instructions on how to complete their tasks (Hershatter \& Epstein, 2010). They tend to challenge authority (Gursoy, Chi, \& Karadag, 2013) and prefer their managers to be open and positive (Broadbridge et al., 2007).

\section{Challenges for retaining Millennials}

Millennials are the fastest-growing segment of the workforce, with a prediction that they will comprise 35\% of workforce by 2020 (Manpower Group, 2016). They possess the talent and the intellect to achieve their goals; thereby Millennials will most likely be one of the greatest assets of organizations in the future (McCracken et al., 2015). The challenge regarding retention mostly stems in the fact that Millennials are known to be rather disloyal to the organization and appear to be prone to switching jobs and/or careers (Gursoy, Maier, \& Chi, 2008; Thompson \& Gregory, 2012). Job mobility is a new normal for them (Lyons et al., 2015), indicating that changing jobs every few years does not represent a burden but rather a challenge and an opportunity to learn something new. According to the Pew Research Centre (2010), nearly 60\% of employed Millennials have already changed jobs at least once in their careers, indicating that they do not plan to stay at the same organization throughout their career. Many organizations are unable to retain these young professional, thereby losing resources due to unwanted turnover of Millennials and lost productivity (Smith \& Galbraith, 2012; Sujansky \& Ferri-Reed, 2009).

It seems that because Millennials are the newest employees in the workforce, employers do not have enough experience with managing these young talents (Campione, 2015). Namely, organizations are mostly failing to create work environment that leverages the potential of Millennials but does not alienate the rest of the workforce (Spiro, 2006; Winter \& Jackson, 2016). These young talents have high expectations with regard to the organizations they want to work for, particularly involving the importance of working conditions (e.g., autonomy, social involvement), opportunities (e.g., career advancement), and flexibility (e.g., providing the freedom to maintain a better balance between work and personal goals) organizations can offer ( $\mathrm{Ng}$ et al., 2010; Twenge et al., 2010). Millennials also value fairness, equitable treatment and honoring any promises made to employees and are prone to leave the job if they do not get it (Luscombe et al., 2013). According to Park and Gursoy (2012), young generations who are highly engaged in work activities will be more satisfied with their job and will thereby show less turnover intention than older generations. Similarly, Thompson and Gregory (2012) argue that "Millennials expect organizations to continually re-engage them and remind them why they should stay" (p. 240).

Scholars argue that Millennials value job security less then members of previous generations (Hart, 2006) and some studies report lack of loyalty and work ethic (Del Campo, Haggerty, Haney, \& Knippel, 2011; Cogin, 2012). Yet, there is recent evidence that shows that uncertainty in economy and fewer job opportunities have caused Millenials to desire greater stability (Deloitte, 2017). Compared to previous years, the percentage of Millennials who expect to leave the employing company in the coming two years was in 2016 substantially lower, potentially indicating an increase in loyalty. 


\section{Psychological contract breach as a framework to study retention of Millennials}

Scholars use psychological contract perspective to study talent management (Höglund, 2012; Rodwell, Ellershaw, \& Flower, 2015) and retention (Festing \& Schäfer, 2014; Blomme, Van Rheede, \& Tromp, 2010; de Vos \& Meganck, 2008; Kraak, Lunardo, Herrbach, \& Durrieu, 2017). It is a particularly useful concept to study retention due to the established link between the breach of psychological contract and employee attitudes, including job satisfaction, commitment and turnover intentions (Robinson \& Morrison, 2000; Zhao et al., 2007; Dulac, Coyle-Shapiro, Henderson, \& Wayne, 2008; Tekleab, Orvis, \& Taylor, 2013). For retention management, existing PC studies focus on how employees perceive employer's obligations regarding pay, job security, personal development etc. PCs are usually classified along two dimensions, transactional and relational, but Rousseau (2000) added the balanced type to reflect changes in the employment relationships and labour market, such as the need for flexibility, new forms of work, knowledge economy, and globalization. Transactional PCs are short-term, narrow with regard to tasks and responsibilities, and mostly materialistically-oriented. Relational PCs are based on loyalty and stability and build relationships beyond economic exchange. Balanced PCs are dynamic and openended employment arrangements that include both the economic success of the firm and employee opportunities to develop career advantages inside organization and externally. Research suggests that relational PCs are positively and transactional PCs negatively related to work outcomes and attitudes (Zhao et al., 2007). Thus, transactional PCs increase turnover intentions.

For retention, the next important concept is a breach of the PC. It occurs with the employee's recognition that the employer has not fulfilled one or more obligations (Morrison \& Robinson, 1997). Following the logic of the social exchange and the norm of reciprocity, when employees perceive that a breach occurs they respond with negative feelings and behaviours (Taylor \& Tekleab, 2004). Employees may perceive a breach of PC as a negative event at work (Zhao et al., 2007) and develop feelings of anger and betrayal that turn breach into perceived violation of the PC (Robinson \& Morrison, 2000). PC breach and/or violation are important concepts explaining negative employee attitudes and outcomes, including turnover (Zhao et al, 2007; Conway \& Briner, 2005).

Research has confirmed that young people without much working experience enter the employment relationship with high and less realistic expectations (De Vos, Buyens, \& Schalk, 2003; Thomas \& Anderson, 1998). According to the life span theory, they are also less capable to manage disappointments at work due to lower ability to regulate emotions (Heckhausen, Wrosch, \& Schulz, 2010). Therefore, a PC breach/violation seems to be more harmful to younger employees than to older ones (Bal \& Smit, 2012). D'Amato and Herzfeldt (2008) summary of research findings on generational differences confirm that the young are keener on moving to a good opportunity elsewhere if their expectations are not met with current employer. Bal, De Lange, Jansen and Van der Velde (2008) performed a meta-analysis of the research on PC breach and job attitudes with age as a moderator. They confirmed that PC breach leads to higher intentions to leave and especially younger workers may respond to contract breaches by becoming less attached to the organization. Bloome et al. (2010) also found that the younger the respondents, the less committed they were to their organization and the more likely they were to leave if they perceived 
the breach of PC. In their study, job content appeared to be the most significant predictor of the intention to leave, followed to a much lesser extent by promotion opportunities and salary.

\section{Study 1: Insights into Millennials’ APC: An empirical analysis}

\section{Methodology}

To answer our first two research questions regarding the characteristics of APC, we used a quantitative research design. Data were collected from April to September 2015 by using a convenience sample of undergraduate business students. The relevance of a student sample for predicting expectations at work has been confirmed by Taris et al. (2006) and Luscombe et al. (2013) who have not discovered any significant differences between students and those employed belonging to the same age cohort (Generation $\mathrm{Y}$ in their studies). Our sample includes countries for which there is little data on APC: Slovenia, Poland, China, and South Korea. To ensure comparability of the data, the survey was conducted in leading business schools that have international quality accreditations or strong international ties: University of Ljubljana in Slovenia, University of Warsaw in Poland, Shanghai University of International Business \& Economics, Beijing Foreign Studies University, and Southwestern University of Finance and Economics (Chengdu) in China, and Chonnam National University (Gwangju) and Kyungpook National University (Daegu) in South Korea.

The questionnaires were administered in the local language after a typical translation - back translation procedure for Slovenian, Polish, Mandarin, and Korean. In each country, we had the country representative researchers who were responsible for distribution of the survey to target participants. In Slovenia, an Internet-based survey was used and in South Korea, Internet-based survey was supplemented by a paper version, while Polish and Chinese students were offered only a paper version of survey. The decision to use different types of survey for collecting data was based on the experiences of the country representative in terms of administering surveys and getting adequate response rates among students. The student participation was voluntary and anonymous.

The aim of the study was to get an insight into students' attitudes and their views of employers. Thus, Rousseau's (2008) PCI - Psychological Contract Inventory - was used to measure the expectations regarding employee and employer obligations. Besides the typical transactional and relational types of PC, this inventory includes a balanced type of PC, which reflects changes in the labour market and fits well with the characteristics of Millennials. The expectations are grouped in seven dimensions and three types of PCs: transactional (short-term and narrow dimensions), relational (loyalty and stability dimensions) and balanced (development, performance and external marketability dimensions). Each dimension features four items and each item is scored on a 5-point scale from 1-not at all to 5-to a great extent. Since we explored APC of students, they were asked to what extent they expect to make the listed obligations to their future employer and to what extent they expect their future employer to make the listed obligations to them. We calculated aggregate means for PC types and dimensions as proposed by the author of the instrument. In addition, students were also asked about the following employment preferences regarding: company size (small, medium, large), sector (public, private), entrepreneurial 
orientation (i.e. owning a company as opposed to working for someone else), and type of job (expert, managerial).

\section{Results}

Altogether, 953 Millennials responded to the survey; 166 questionnaires were excluded from further analysis due to missing values. The final sample consisted of 180 respondents in Slovenia, 209 in Poland, 177 in China and 221 in South Korea. Thus, in the present study, we employ a sample that consists of 787 Millennials, who are pursuing business education. In terms of demographic characteristics of the respondents, $41 \%$ of are male and $59 \%$ female, most of respondents were born from 1992 and 1994. As indicated above, the data were gathered from business students in four selected countries, two from Central and Eastern Europe (i.e. Slovenia and Poland) and two from East Asia (i.e. China and South Korea). 52\% of respondents in the sample belong to the CE European sample, while $48 \%$ comprise the East Asian sample.

In terms of future employment preferences, $22 \%$ of respondents would prefer to work in a small company, $50 \%$ in a medium-sized and $28 \%$ in a large company. We also inquired about the preferred type of job. Specifically, $51 \%$ of Millennials prefer an expert job, and $49 \%$ executive/leadership position. Further, $55 \%$ would prefer to have their own company (selfemployed), while $45 \%$ prefer working in an existing company. In terms of sector, $29 \%$ would prefer being employed in a public and $71 \%$ in private sector.

In answering the first research question, we look into the dimensions of APC based on two perspectives. The first one includes Millennials' perceptions of what is a future employer obliged to offer them (i.e. employer obligations), while the second one contains Millennials' views of what commitments they are willing to make to a potential employer (i.e. employee obligations). In both instances, we asked respondents to consider potential employers, as they were pursuing education at the time and will only enter the labour market in the future.

In Table 1, we report the average values of seven dimensions of obligations, employers' and employees' respectively. Findings reveal that Millennials prefer balanced types of APC for both employee and employer obligations, followed by relational and transactional. For employee obligations, all three dimensions of the balanced APC got a higher average score than other relational and transactional dimensions. The highest score of 4.21 is for the dimension development, which included four items: seeking out developmental opportunities that enhance my value to this employer, building skills to increase my value to this organization, making myself increasingly valuable to my employer and actively seeking internal opportunities for training and development. Interestingly, the second highest score (3.89) is for the dimension external marketability, which includes building skills and seeking assignments to increase employability, developing contacts outside the organization and increasing visibility on the market. Performance support dimension is the third highest score and it pertains to willingness to accept more demanding performance standards and challenges. Within the relational type APC, loyalty scored higher (3.48) than stability (3.05). Loyalty is described by protecting company image, commitment, care and sacrifice for the organization, and stability by remaining with this organization for a long time or indefinitely, continuing to work here and making no plans to work anywhere else. The least difference between the scores for dimensions is within the transactional type of APC, both short- 
term (2.85) and narrow (2.76) scored below 3, indicating that students mostly do not expect to quit/leave whenever they want and have no future obligations to this employer, or have narrowly defined tasks and responsibilities.

[Insert Table 1 near here]

For employer obligations, which with the exception of stability mirrors the obligations for employees, development again got the highest score (4.19) of all dimensions, but the second highest is stability (4.05). Stability includes four items: secure employment, wages and benefits I can count on, steady employment, and stable benefits for employees' families. The third highest score is for performance support (3.91), followed by external marketability (3.69). Again, score for both transactional dimensions are close or below 3, with short-term scoring the lowest (2.48) and narrow (3.03).

The second research question entailed the differences among Millennials in regards to APC, employment preferences, gender and geographical location. First, we investigated the differences between male and female Millennials and found that their assessments of obligations of potential employers differ only in one APC dimension. Specifically, for the short-term dimension, there are significant differences between males and females, with the score being lower for females $(\mathrm{M}=2.44)$, meaning that the employers' obligations related to short-term dimension with a mostly materialistic focus are more important for males $(M=2.51)$ then they are for females $(\mathrm{t}=-1.204 ; \mathrm{p}=0.038)$. In addition, male and female Millennials expectations differ only regarding the employers' obligations for the transactional type of APC $(\mathrm{t}=-1.736 ; \mathrm{p}=0.055)$. Women expect this type more as an element of their employment relationship $(M=2.792$ for female; $M=2.71$ for male). We further checked the gender differences in regards to employment preferences (Table $2)$. The only marginally significant difference was in the sector $(t=-2.714 ; \mathrm{p}=0.109)$.

[Insert Table 2 near here]

To further explore the potential differences among Millennials regarding their APC and employment preferences, we conducted a two-step cluster analysis. In terms of geographical location, we grouped responses in two categories, merging data from Poland and Slovenia in one group (termed Europe) and joining data for Chinese and Korean respondents, which represents another group (termed Asia). The analysis of the sample data identified two relatively equallysized clusters of young talents, one comprising 50.1\% (394) and the other one $49.9 \%$ (392) respondents. The ration of largest to smallest cluster was acceptable at 1.01 . We used the following 8 variables: psychological contract types, geographical location, employment preferences (i.e. public/private sector, company size, entrepreneurial tendencies, type of job).

Based upon the analysis two distinct clusters of Millennials were revealed (Table 3). We termed the first cluster the EA cluster and the second one the CEE cluster. Interesting differences were uncovered with regard to the types of psychological contract regarding employer obligations and employment characteristics. Specifically, we find that Millennials in EA have a strong tendency for balanced psychological contracts, followed by a relational contract. The average values for these two types are high and lie at 4.06 and 4.03 respectively. The elements of transactional contract received the least recognition in the EA as well as the CEE cluster and the average scores were practically identical, demonstrating that short-term and narrow obligations in terms of limited involvement and little training are not desired and expected. The CEE cluster 
differs from the EA one in terms of relatively lower average scores attributed to balanced (3.80) and relational types (3.56).

Finally, while the two clusters are similar in the fact that respondents in CEE as well as EA tend to prefer working in a medium sized company, differences were observed in other preferences, one of them being the lower preference of CEE Millennials for working in public sector as opposed to EA Millennials. While CE Europeans are practically unanimous in their preference to work in private sector, in EA only about a half of respondents prefer this option to public sector work. Two thirds of respondents in CEE would prefer an executive position, while two thirds of EA respondents are more keen on expert positions. A preference for an entrepreneurial career was indicated by $69 \%$ of CEE and $58 \%$ of EA Millennials.

[Insert Table 3 near here]

\section{Study 2: Insights into a Potential breach of PC for Millennials - the example of Slovenia}

\section{Methodology}

To explore the third research question, which considered the potential risks for psychological contract breach for Millennials, we report results from a supplemental study, conducted in one of the countries, Slovenia. In order to identify possible elements of APC where a breach could occur due to differences in expected mutual obligations, data were gathered from employers in Slovenia ${ }^{1}$. Again, the PC Inventory questionnaire by Rousseau (2008) was used for employers as one part of a broader study on talent management. A convenience sample was used in order to target companies that are active on the labor market. Through partnership with one of the leading private employment agencies, which distributed the questionnaire among their customers, responses from HR managers in 101 companies were collected. The final sample therefore consists of mostly private sector companies ( $81 \%$ ), about half of them are considered large employers by Slovenian standards (over 250 employees), $28 \%$ medium (from 50 to 249 employees) and $10 \%$ each small (10-49 employees) and micro companies (up to 9 employees). Data was gathered from January to February 2017.

\section{Results}

When we compare HR managers' and students' opinions regarding employer and employee obligations, we observe some differences when looking at PC dimensions (Table 4). For both, HR managers and students, development got a score slightly above 4 for both employee and employer obligations and it is thus the highest scored dimension overall. For these expectations regarding development, it also seems that there is good agreement both between and within groups. However, if we look at individual items, HR managers expect more with regard to learning as employee obligation and students with promotion and development opportunities as employer's obligation. The biggest differences between HRM managers and students expectations are for the dimension external marketability. While students expect that building on external marketability is a strong

\footnotetext{
${ }^{1}$ Quantitative data were collected by two master students at University of Ljubljana, Slovenia as a part of their graduation thesis.
} 
element of employer obligations (mean score of 4.02), HR managers do not (mean score of 2.98). Students also expect the employer to build employee external marketability much more than HR managers see it as an employer obligation. Quite the opposite are the results for performance support, where HR managers expect high performance and constant striving to increase it to be an obligation for both employees and employers much more than students do (the highest score for dimensions from HR managers 4.16 for employer and 4.00 for employee obligations, while scores for students are 3.59 for both obligations).

[Insert Table 4 near here]

For relational dimensions, scores are rather similar for stability, but for loyalty HR managers score much higher than students. Among four items in this dimension, it is the care for company's reputation, which contributes the most to this difference for employee obligations. Protecting company's image is the most important obligation for HR managers (score 4.43). For employer obligations, the difference stems from students' lower evaluation of obligations for personal concerns and well-being of employees. Within the four items for the stability dimension, it seems that while HR managers see secure employment and wages as stronger obligation, students perceive benefits for the family to be important.

For both transactional dimensions (short-term and narrow), students' expectations are higher than HR managers' for employer and employee obligations are. A more detailed look at items in each dimension shows that students expect employers more to have a job for them only for a short period of time and only as long as they need them. In addition, they expect employees to be more free to leave the job when they desire and without any future obligations. For the narrow dimension, students expect employee and employer obligations to be more characterized by only limited involvement in the organization and a limited set of duties.

If only employer obligations for all items are considered, we can identify potential PC breach situations (Figure 1) which could lead to higher turnover intentions. Out of seven items with a possibility for unmet employee expectations, there are all four items from the dimension external marketability; students expect employers to offer to them opportunities and contacts for potential work outside the organization and to develop externally marketable skills. Students also expect opportunities for promotion, development within the firm, and family benefits to a larger extent than employers are expected to provide them. A risk of the potential breach of PC leading to violation and possible turnover is higher because most of these seven items rank among the top expectations of the students from their employer.

\section{[Insert Figure 1 near here]}

\section{Discussion, limitations and suggestions for future research}

In order to solve challenges pertaining to retention of young talents, it is important to understand their employment expectations and our study offers several insights in this regard with important implications for talent retention. In the first study, we analysed the APC and employment preferences of undergraduate students from leading business schools in two CEE countries 
(Slovenia and Poland) and two EA countries (China and South Korea). Results show that the preferred type of APC for Millennials in these four countries is the balanced one, followed by the relational and the transactional as the last one. These holds true for both employee and employer obligations, although the difference between the scores for balanced and relational type is larger for employee ( 0.48 ) than employer (0.14) obligations. The difference can be attributed to relatively lower score for external marketability and higher for stability for employer compared to employee obligations. Results are somewhat surprising as some previous research suggested that Millennials would prefer more transactional than relational PCs (e.g. Bal \& Kooij, 2011). Since transactional PCs are linked to higher turnover intentions, our results could be somewhat encouraging regarding Millennials' retention.

Overall, results demonstrate relatively high expectations regarding balanced and relational dimensions of APC. Detected high expectations are confirming some previous studies (Ng et al., 2010). Yet, high expectations could pose a challenge from the retention management perspective. Winter and Jackson (2016) report that employers see these high expectations as unrealistic and the main reason for higher turnover as they cannot be met by employers. Some managers even talked about excessive and unhealthy expectations implying a mismatch with realities of employment relationships. The challenge of meeting high expectations can be also depicted from the results of our second study on comparing Millennials and HR managers' expectations regarding employer obligations.

Additional insights can be drawn from analysing PC dimensions. Based on our results, performance support scores are relatively low compared to other dimensions, possibly indicating lower work centrality mentioned by other studies (e.g. Twenge, 2010). However, lower work centrality is supposedly linked to more transactional contracts (Bal \& Kooij, 2011) which scored significantly lower than relational and balanced in our sample. This may suggest that in developing employment expectations, lower work centrality is offset with Millennials' strong ambition and needs for advancement and development. In addition, stability has a relatively high score among APC dimensions for employer obligations. This could be a sign that Millennials are not necessarily having inherently strong turnover intentions. However, willingness to stay in the company may decrease if their expectations are not met (Campione, 2015). Even more worrisome are highly expressed expectations regarding external marketability (especially for employee obligations). Combined with the fact that stability is much more expected from employers than is seen as an employee obligation by Millennials, these indicate the risk of undesired turnover. High scores of both development and external marketability suggest that their own development is important to Millennials, but also with the goal to increase their employability as was suggested by previous research (Holden \& Harte, 2004; Cennamo \& Gardner, 2008). It confirms that Millennials are not so attached to the organization but rather pursue their career aspirations wherever they find good opportunities (Luscombe et al., 2013; Blomme et al., 2010).

Cluster analysis shows that EA students have higher expectations than CEE students, which could reflect both differences in cultures and socio-economic context. Namely, EA culture is known to be more collectivistic (House, Hanges, Javidan, Dorfman, \& Gupta, 2004) and is based on Confucianism, hence it is characterized by loyalty, relationship building, the importance of learning and work ethics (Ralston, Holt, Terpstra, \& Yu, 1997; Cooke, Saini \& Wang, 2014). Another source of variation could lie in the economic and labour market conditions in observed 
countries. Compared to China and South Korea, both Poland and Slovenia have witnessed stronger effects of the financial and economic crises, with slower economic growth and higher youth unemployment (World Bank, n.d.), which may have contributed to lower expectations (Zupan, Dziewanowska, \& Pearce, 2017). Due to limited space we have presented only a cluster analysis for geographical regions and gender differences. Nevertheless, descriptive statistics for our sample show that there is some variability in responses with regard to expectations and employment preferences, which implies caution regarding overgeneralization or even worse, stereotyping when dealing with individuals.

In the second study, we combined student and employer components of PC for Slovenia in order to identify potential PC breach situations. Our second study, which compares Millennials' and employers' expectations, confirms that employers may not be willing or able to meet some of the Millennials' expectations, especially with regard to external marketability, development and promotion and stable benefits for the family. On the other hand, a relatively big gap between both sides regarding performance support, marketability and loyalty expectations could pose a provocative question. Namely, should employers in Slovenia even wish to employ Millennials who are more focused on their own development and employability than on what they will contribute to their employers in terms of performance and loyalty. However, employers may have a little choice since Millennials entering the labour market constitute the largest pool of candidates. It is also worth mentioning, that Slovenian sample seems to be standing out compared to other three countries in our study with regard to relatively low scores of performance support and loyalty, suggesting that national culture and context matters in order to explain PC components (Thomas, Au \& Rovlin, 2003).

We have presented some notable contributions to understanding APC of Millennials in general and with regard to retention. However, the present research is not without limitations. The first one concerns the selected samples. While we obtained samples from two countries in CEE and two in EA, we cannot assume that these are representative countries for each of the respective regions. Therefore, in order to make generalizations, future research could systematically explore the APC in different countries of the two regions. This could further increase understanding of the characteristics of Millennials from non-Western countries which are underrepresented in current academic literature. In addition, when doing cross-national research on APC, more attention should be devoted to the socio-economic context of countries (e.g. economic growth, labour market indicators) as it may play a significant role in APC formation and the level of importance ascribed to different PC dimensions (De Hauw \& De Vos, 2010; Eilam-Shamir \& Yaakobi, 2014). In this regard it would be interesting to investigate how PC expectations change depending on favourable and less favourable economic circumstances.

Second, while our analysis tested for potential differences in APC based on employment preferences, other variables need to be considered. For example, future research could uncover how personality factors affect the prominence of certain APC dimension. Further, contextual variables deserve more attention as well. Here, we recommend that cultural characteristics (e.g. national values) and perceived economic situation and certain economic indicators, could provide more information regarding the more and less important dimensions and types.

The third limitation concerns the sample of Study 2, which is based on an example from a single country, Slovenia. While the results concerning potential breach are informative, we need 
further analyses on other samples that are larger in size to verify the relationships. It may also be expected that the reasons for potential breach and reactions to the breach would differ across national and geographical contexts, so these variables should be included in future studies as well. Another important venue for future research is to include measures for a PC breach and reactions to it for both future and newly employed Millennials from different countries and organizations, thereby controlling for organizational and country specific factors that may have influenced our results.

Finally, in this study we used an established measure of Psychological contracts, yet, it may be useful to consider updating the dimensions and including novel expectations that fit more to the desires and ambitions of the current young generation. Due to their unique characteristics, we recommend that researchers develop a PC questionnaire specifically for the Milennial employees. A new PC inventory for Millennials would therefore measure expectations that are typical for this cohort. For example, the PC inventory by Rousseau (2008) which was used for this research, does not examine issues related to work-life balance, social meaningfulness, and work environment which are very important to this group of talents. Similarly, in the existing questionnaires used in other APC studies there are no items related to marketability or employability, which are relevant for Millennials.

Future research should also examine how Millennials' characteristic shape their expectations regarding the employer obligations. In order to manage these high expectations, it is crucial that we understand the factors that influence APC. Furthermore, comparative studies of APC and PC of Millennial newly employed would shed more light on how PC are formed and changed over time. In addition, a mixed methods research could provide more in-depth insights into understanding PC formation and differences stemming from demographics and national culture and socio-economic context.

\section{Implications for retention theory and practice}

Managers and HR professionals need to to be well aware of what Millennials expect, desire and find challenging at work, if they want to retain them in respective organizations. However, Zhao (2006) found that organizations underestimate the expectations of graduates and their impact on outcomes and behaviour. Based on our study, we suggest that APC could be a useful tool to improve existing understanding of Millennials' expectations. By adjusting their talent and retention management strategies and practices accordingly, they will be more successful in retaining the young talents. It seems that employers are not realizing this opportunity and they have not yet adjusted their approach and talent management to Millennials. For example, of 101 companies in our Slovenian sample (study 2), only $26 \%$ responded that they use tailored HR practices for Millennials. In addition, better understanding could lead to better fulfilment and organizations could benefit from their young talents' increased engagement and performance as well as lower turnover intentions. including paying attention to individual needs and expectations

as suggested by Thunissen (2016) and offering I-deals (Rousseau, Ho, \& Greenberg, 2006), However, Millennials' expectations may prove to be in many instances too high, therefore an important action from employers is required already with early recruitment HR practices when cooperating with universities and students (e.g. company presentations, projects and internships). 
Thereby, employers can influence APC to be more realistic and thus reduce the risk of psychological contract breach upon employing young talents.

Next, as an expectations lowering procedure (Buckley, Mobbs, Mendoza, Novicevic, Carraher, \& Beu, 2002), discussion about expectations and PC should be part of the recruitment process in order to clarify these expectations on both sides. Realistic job preview is a useful tool for lowering expectations and has a positive effect on reduced turnover (Baur, Buckley, Bagdasarov \& Dharmasiri, 2014). A realistic job preview needs to be followed by realistic promises regarding PC elements, especially with regard to development and promotion. Our study shows that a lot of Millennials, especially in CEE, prefers a managerial over professional/expert career. If it unclear from the beginning how long could it possibly take and what needs to be done to get to a managerial position, the risk of a perceived breach of the $\mathrm{PC}$ is higher. High promises and overly favourable descriptions of what to expect are often made just to attract Millennials (Tekleab et al., 2013), but this can easily backfire since they are sensitive to not being treated fairly or to their employers not keeping promises (Luscombe et al., 2013). By knowing APC of business students, i.e. the way young talents perceive their future obligations towards employers on the one hand and employers' obligations on the other, employers can develop such talent management practices, which speak to Millennials' values. In addition to recruiters, managers have an important role in shaping more realistic expectations (Rousseau, 1995) through implementing HR practices, including on-boarding, managing performance, rewarding, mentoring and developing newcomers. If properly implemented, these reduce the risk of turnover and can turn challenges into opportunities (Stewart, Oliver, Cravens, \& Oishi, 2017).

Despite the above, some HR practitioners may oversimplify their approach to managing Millennials and focus their retention efforts exclusively on pay raises and promotional opportunities. However, these may not necessarily serve as remedies for retaining Millennials. Our study indicates that pay and promotion are expected from employers to a lesser degree than personal development and performance support. Pay may attract Millennials initially, but Campione (2015) found its weaker significance relative to other factors for retention purposes. However, while it may not be the most important, pay is also not trivial. Lub et al. (2016) found that if Millennials perceive that their pay is not fair it would increase their intentions to leave.

As evident from our research, there is some variability among Millennials and if employers devote effort to find a good match, they could reduce the risk of losing young talents too quickly. By knowing similarities and differences in APC, employers can decide on the level of individualization of the employment relationship needed to retain young talent. By doing so they can avoid the negative consequences of I-deals, which may create tensions among co-workers due to preferential treatment and could add too much complexity to HRM systems (Rousseau et al., 2006).

Finally, variability in APC dimension and item scores suggests that a PC breach has to be understood as a multidimensional construct (Kraak, Lunardo, Herrbach \& Durrieu, 2017). Therefore, elements of the PC should be identified where Millenials would actually feel PC violation, which would lead to increased turnover intentions. For example, Lub, Bal, Blomme \& Schalk (2016) found that for Millennials the fulfilment of career development obligations have a stronger impact on work outcomes compared to other generations. If such incentives are provided, it may be expected that they enhance affective commitment. However, in their study the predictive value of development for turnover intentions was weak, so it seems that Millennials would still change employer if they considered the employment there to be a better opportunity. 


\section{Conclusion}

The topic of managing Millennial talents is relatively new and although the challenges of retention are often cited, not enough is known about antecedents and mechanism that lead to turnover intentions and actual turnover. An analysis of psychological contracts, and more specifically the anticipatory psychological contracts that were the focus of this study, contributes to a better understanding of Millennials' expectations at work and their retention. By taking into consideration the expectations that are formed at the pre-employment stage, employers could take an active role early on (during university years) to 1), make those expectations realistic and 2) to adjust their talent management, HR practices and management/leadership styles to the preferences of Millennials to reduce the risk of a psychological contract breach. As results suggest, Millennials are thinking about their development mostly in terms of employability and might use early years of employment more as a catalyst for their future careers rather than contributing to current employers. Employers could thus capture the potential of young talents only through properly implemented and potentially individualized talent management practices. In addition, while there are similarities among Millennials around the world, our research affirms that there are also some notable differences, national and contextual specifics should be considered.

\section{Chapter summary}

In order to address challenges related to Millennials' retention, it is important to recognize their preferences regarding employment expectations and employer-employee relationships. The concept of anticipatory psychological contracts (APC) provides a rich understanding of young talents' expectations, comprising both the obligations the young have of themselves as potential employees and of employers. The present research found that the preferred type of APC for Millennials in Central and Eastern Europe (CEE) and East Asia (EA) is the balanced one, with results indicating high scores for development and external marketability dimensions. Regarding the second, relational type, the score is considerably higher for employer than employee obligations, showing that Millennials expect more stability and loyalty than they are willing to give. The transactional type is least preferred, indicating that Millennials may not be inherently prone to turnover. Rather, Millennials are most focused on their personal development to increase employability and could be loyal only if they get what they expect from employers. If not, they would capitalize on their external marketability and search for opportunities elsewhere. That the above mentioned second scenario is likely to occur can be inferred from the identified potential breach of psychological contract, specifically when comparing APC dimensions perceived by Millennials and their potential employers. To retain young talents, it is important for employers to make Millennials' expectations more realistic via pre-recruitment activities. Then they should discuss PC elements during recruitment and provide realistic job previews. Once Millennials are employed, employers should develop and implement tailored talent management practices to effectively respond to their needs and expectations. Moreover, in developing talent management 
practices, national and socio-economic contexts should be considered as they both affect the formation of expectations.

\section{Acknowledgements}

The authors would like to thank our research colleagues for their contribution to data collection and helping us understand country/region specific results: Matej Černe, Robert Kaše, Matevž Rašković, Katarzyna Dziewanovska, Lorne Hwang, Seong-Do Cho, Ilsang Ko. Also, special thanks to Martin Virag and Katja Podrepšek for their efforts to collect data from employers in Slovenia. The development of theoretical framework and literature review was supported by European Union's Horizon 2020 research and innovation programme under the Marie Skłodowska-Curie grant agreement No 734824.

\section{References}

Bal, M.P., \& Smit, P. (2012). The older the better! Career Development International, 17(1), 6-24.

Bal, M.P., De Lange, A.H., Jansen, P. G. W., \& Van Der Velde, M. E. G. (2008). Psychological contract breach and job attitudes: A meta-analysis of age as a moderator. Journal of Vocational Behavior, 72(1), 143-158.

Becton, J.B., Walker, H.J. \& Jones-Farmer, A. (2014). Generational differences in workplace behavior. Journal of Applied Social Psychology, 44(3), 175-189.

Blomme, R.J., van Rheede, A., \& Tromp, D.M. (2010). The use of the psychological contract to explain turnover intentions in the hospitality industry: a research study on the impact of gender on the turnover intentions of highly educated employees. The International Journal of Human Resource Management, 2l(1), 144-162.

Broadbridge, A.M., Maxwell, G.A., \& Ogden, S.M. (2007). 13_2_30: experiences, perceptions and expectations of retail employment for generation Y. Career Development International, 12(6), 523-44.

Buckley, M.R., Mobbs, T.A., Mendoza, J.L., Novicevic, M.M., Carraher, S.M. \& Beu, D.S. (2002). Implementing realistic job previews and expectation-lowering procedures: a field experiment. Journal of Vocational Behavior, 61(2), 263-278.

Campione, W. A. (2015). Corporate Offerings: Why Aren't Millennials Staying?. The Journal of Applied Business and Economics, 17(4), 60-75.

Cennamo, L., \& Gardner, D. (2008). Generational differences in work values, outcomes and personorganisation values fit. Journal of Managerial Psychology, 23(4), 891-906.

Cogin, J. (2012). Are generational differences in work values fact or fiction? Multi-country evidence and implications. The International Journal of Human Resource Management, 23(11), 2268-2294.

Conway, N., \& Briner, R. B. (2005). Understanding psychological contracts at work. A critical evaluation of theory and research. Oxford, United Kingdom: Oxford University Press.

Cooke, F.L., Saini, D.S., \& Wang, J. (2014). Talent management in China and India: A comparison of management perceptions and human resource practices. Journal of World Business, 49(2), 225235.

D'Amato, A., \& Herzfeldt, R. (2008). Learning orientation, organizational commitment and talent retention across generations. Journal of Managerial Psychology, 23(8), 929-953.

Del Campo, R. G., Haggerty, L. A., Haney, M. J., \& Knippel, L. A. (2011). Managing the multi-generational workforce. Surrey, United Kingdom: Gower. 
De Hauw, S., \& De Vos, A. (2010). Millennials' Career Perspective and Psychological Contract Expectations: Does the Recession Lead to Lowered Expectations? Journal of Business Psychology, 25(2), 293-302.

Deloitte. (2017). The Deloitte Millennial Survey 2017. Retrieved May 6, 2017, from https://www2.deloitte.com/global/en/pages/about-deloitte/articles/millennialsurvey.html.

De Vos, A., Buyens, D., \& Schalk, R. (2003). Psychological contract development during organizational socialization: Adaptation to reality and the role of reciprocity. Journal of Organizational Behaviour, 24(5), 537-559.

De Vos, A., \& Meganck, A. (2008). What HR managers do versus what employees value: Exploring both parties' views on retention management from a psychological contract perspective. Personnel Review, 38(1), 45-60.

De Vos, A., De Stobbeleir, K., \& Meganck, A. (2009). The relationship between career-related antecedents and graduates' anticipatory psychological contracts. Journal of Business and Psychology, 24(3), 289-298.

Dulac, T., Coyle-Shapiro, J. A. M., Henderson, D. J., \& Wayne, S. J. (2008). Not all responses to breach are the same: The interconnection of social exchange and psychological contract processes in organizations. Academy of Management Journal, 51(6), 1079-1098.

Eilam-Shamir, G., and Yaakobi, E. (2014). Effects of early employment experiences on anticipated psychological contracts. Personnel Review, 43(4), 893-912.

Festing, M., \& Schäfer, L. (2014). Generational challenges to talent management: A framework for talent retention based on the psychological-contract perspective. Journal of World Business, 49(2), 262271.

Gallardo-Gallardo, E., Nijs, S., Dries, N. \& Gallo, P. (2015). Towards an understanding of talent management as a phenomenon-driven field using bibliometric and content analysis. Human Resource Management Review, 25(3), 264-279.

Graen, G. B., \& Schiemann, W. A. (2013). Leadership-motivated excellence theory: An extension of LMX. Journal of managerial psychology, 28(5), 452-469.

Gursoy, D., Maier, T., \& Chi, C. (2008). Generational differences: An examination of work valuesand generational gaps in the hospitality workforce. International Journal of Hospitality Management, 27(3), 448-458.

Gursoy, D., Chi, C. G. Q., \& Karadag, E. (2013). Generational differences in work values and attitudes among frontline and service contact employees. International Journal of Hospitality Management, $32(1), 40-48$.

Hart, S. M. (2006). Generational diversity: impact on recruitment and retention of registered nurses. Journal of Nursing Administration, 36(1), 10-12.

Heckhausen, J., Wrosch, C., \& Schulz, R. (2010). A motivational theory of life-span development. Psychological Review, 117(1), 32-60.

Hershatter, A., \& Epstein M. (2010). Millennials and the World of Work: An Organization and Management Perspective. Journal of Business and Psychology, 25(2), 211-223.

Holden, R., \& Harte, V. (2004). New graduate engagement with 'professional development'. Journal of European Industrial Training, 28(2/3/4), 272-282.

Höglund, M. (2012). Quid pro quo? Examining talent management through the lens of psychological contracts. Personnel Review, 41(2), 126-142.

House, R. J., Hanges, P. J., Javidan, M., Dorfman, P. W. \& Gupta, V. (2004). Culture, Leadership, and Organizations: The GLOBE Study of 62 Societies. Thousand Oaks, CA: Sage.

Johnson, M., \& Johnson, L. (2010). Generations, Inc.: From boomers to linksters--Managing the friction between generations at work. New York, NY: AMACOM.

Kong, H., Wang, S., \& Fu, X. (2015). Meeting career expectation: can it enhance job satisfaction of Generation Y?. International Journal of Contemporary Hospitality Management, 27(1), 147-168. 
Kraak, J. M., Lunardo, R., Herrbach, O., \& Durrieu, F. (2017). Promises to employees matter, self-identity too: Effects of psychological contract breach and older worker identity on violation and turnover intentions. Journal of Business Research, 70(1), 108-111.

Kuron, L. K., Lyons, S. T., Schweitzer, L., \& Ng, E. S. (2015). Millennials' work values: differences across the school to work transition. Personnel Review, 44(6), 991-1009.

Lub, X.D., Bal, M.P., Blomme, R.J., \& Schalk, R. (2016). One job, one deal...or not: do generations respond differently to psychological contract fulfillment? The International Journal of Human Resource Management, 27(6), 653-680.

Luscombe, J., Lewis, I., \& Biggs, H.C. (2013). Essential elements for recruitment and retention: Generation Y. Education + Training, 55(3), 272-290.

Lyons, S. T., Schweitzer, L., \& Ng, E. S. (2015). How have careers changed? An investigation of changing career patterns across four generations. Journal of Managerial Psychology, 30(1), 8-21.

Lyons, S., \& Kuron, L. (2014). Generational differences in the workplace: A review of the evidence and directions for future research. Journal of Organisational Behaviour, 35(S1), S139-S157.

Manpower Group. (2016). Millennial Careers: 2020 Vision; Facts, Figures and Practical Advice. Retrieved December 12, 2017, from http://www.manpowergroup.com/wps/wcm/connect/ 660ebf65-144c-489e-975c-9f838294c237/MillennialsPaper1_2020Vision_lo.pdf?MOD= AJPERES.

McCracken, M., Currie, D., \& Harrison, J. (2016). Understanding Graduate Recruitment, Development and Retention for the Enhancement of Talent Management: Sharpening "the edge" of Graduate Talent. International Journal of Human Resource Management, 27(22), 2727-2752.

Morrison, E. W., \& Robinson, S. L. (1997). When employees feel betrayed: A model of how psychological contract violation develops. Academy of Management Review, 22(1), 226-256.

Ng, E. S., Schweitzer, L., \& Lyons, S. T. (2010). New generation, great expectations: A field study of the millennial generation. Journal of Business and Psychology, 25(2), 281-292.

Park, J., \& Gursoy, D. (2012). Generation effects on work engagement among US hotel employees. International Journal of Hospitality Management, 31(4), 1195-1202.

Pearson, J. C., Carmon, A., Tobola, C., \& Fowler, M. (2010). Motives for communication: Why the millennial generation uses electronic devices. Journal of the Communication, Speech \& Theatre Association of North Dakota, 22(1), 45-55.

Pew Research Center. (2010). Millennials: A portrait of Generation Next. Retrieved on November 4, 2017, from http://www.pewresearch.org/topics/millennials/

Ralston, D.A., Holt, D.H., Terpstra, R.H., \& Yu, K.C. (1997). The Impact of National Culture and Economic Ideology on Managerial Work Values: A Study of the United States, Russia, Japan, and China. Journal of International Business Studies, 28(1), 177-207.

Robinson, S.L., \& Morrison, E.W. (2000). The development of psychological contractbreach and violation: a longitudinal study. Journal of Organizational Behavior, 21(5), 525-546.

Rodwell, J., Ellershaw, J. \& Flower, R. (2015). Fulfill psychological contract promises to manage in demand employees". Personnel Review, 44(5), 689-701.

Rousseau, D.M. (1995). Psychological Contracts in Organizations: Understanding Written and Unwritten Agreements. Thousand Oaks, CA: Sage.

Rousseau, D.M. (2008). Psychological Contract Inventory, Employee and Employer Obligations. Pittsburgh, PA: The Heinz School, Carnegie Mellon University.

Rousseau, D. M., Ho, V. T., \& Greenberg, J. (2006). I-deals: Idiosyncratic terms in employment relationships. Academy of Management Review, 31(4), 977-994.

Shaw, S. \& Fairhurst, D. (2008). Engaging a new generation of graduates. Education + Training, 50(5), 366-378.

Sherman, U. P., \& Morley, M. J. (2015). On the Formation of the Psychological Contract: A Schema Theory Perspective. Group \& Organization Management, 40(2),160-192.

Smith, S. D., \& Galbraith, Q. (2012). Motivating millennials: Improving practices in recruiting, retaining, and motivating younger library staff. The Journal of Academic Librarianship, 38(3), 135-144. 
Smola, K. W., \& Sutton, C. D. (2002). Generational differences: Revisiting generational work values for the new millennium. Journal of Organizational Behavior, 23(4), 363-382.

Spiro, C. (2006). Generation Y in the Workplace. Defense AT\&l, 35(6), 16-19.

Stewart, J. S., Oliver, E. G., Cravens, K. S., \& Oishi, S. (2017). Managing millennials: Embracing generational differences. Business Horizons, 60(1), 45-54.

Sujansky, J., \& Ferri-Reed, J. (2009). Keeping the Millennials: Why companies are losing billions in turnover to this generation-and what to do about it. Hoboken, NJ: John Wiley \& Sons.

Taylor, M. S., \& Tekleab, A. G. (2004). Taking stock of psychological contract research: Assessing progress, addressing troublesome issues, and setting research priorities. In J. A. Coyle-Shapiro, L. M. Shore, M. S. Taylor, and L. E. Tetrick (Eds.), The employment relationship: Examining contextual and psychological perspectives (pp. 253-283). Oxford, United Kingdom: Oxford University Press, Oxford.

Tekleab, A., Orvis, K., \& Taylor, M., (2013). Deleterious Consequences of Change in Newcomers' Employer-Based Psychological Contract Obligations. Journal of Business \& Psychology, 28(3), 361-374.

Taris, T.W., Feij, J.A., \& Capel, S. (2006). Great expectations - and what comes of it: the effects of unmet expectations on work motivation and outcomes among newcomers. International Journal of Selection and Assessment, 14(3), 256-68.

Thomas, D. C., Au, K. \& Ravlin, E.C. (2003). Cultural variation and the psychological contract. Journal of Organizational Behavior, 24(4), 451-471.

Thomas, H. D. C., \& Anderson, N. (1998). Changes in newcomers' psychological contracts during organizational socialization: a study of recruits entering the British Army. Journal of Organizational Behavior, 19(S1), S745-S767.

Thompson, C., \& Gregory, J. B. (2012). Managing Millennials: A framework for improving attraction, motivation, and retention. The Psychologist-Manager Journal, 15(4), 237-246.

Thunnissen, M. (2016). Talent management: For what, how and how well? An empirical exploration of talent management in practice. Employee Relations, 38(1), 57 - 72.

Twenge, J. M. (2010). A Review of the Empirical Evidence on Generational Differences in Work Attitudes. Journal of Business Psychology, 25(2), 201-210.

Twenge, J. M., Campbell, S. M., Hoffman, B. J., \& Lance, C. E. (2010). Generational differences in work values: Leisure and extrinsic values increasing, social and intrinsic values decreasing. Journal of Management, 36(5), 1117.

van Stormbroek, R., \& Blomme, R. (2017). Psychological contract as precursor for turnover and selfemployment. Management Research Review, 40(2), 235-250.

Winter, R.P., \& Jackson, B.A. (2016). Work values preferences of Generation Y: performance relationship insights in the Australian Public Service. The International Journal of Human Resource Management, 27(17), 1997-2015.

World Bank. (n.d.). GDP per capita growth (annual \%). Retrieved on December 17, 2017, from http://data.worldbank.org/indicator

Zhao, H. (2006). Expectations of recruiters and applicants in large cities of China. Journal of Managerial Psychology, 21(5), 459-475.

Zhao, H., Wayne, S.J., Glibkowsky, B.C., \& Bravo, J. (2007). The impact of psychological contract breach on work-related outcomes: a meta-analysis. Personnel Psychology, 60(3), 647-680.

Zupan, N., Kase, R., Raskovic, M., Yao, K., \& Wang, C. (2015). Getting ready for the young generation to join the workforce: A comparative analysis of the work values of Chinese and Slovenian business students. Journal of East European Management Studies, 20(2), 174-201.

Zupan, N., Dziewanowska, K. \& Pearce, A. (2017). Wanting it all: the challenges of managing young talent in transition economies. Baltic Journal of Management, 12(1), 63-85. 
Table 1: Comparing students' expectations regarding employee and employer obligations

\begin{tabular}{|l|l|l|l|l|l|}
\hline & & \multicolumn{2}{l|}{ Employee obligations } & \multicolumn{2}{l|}{ Employer obligations } \\
\hline Types of PCs & Dimensions of PC & Mean & St. dev. & Mean & St. dev. \\
\hline Transactional & & 2.81 & $(0.64)$ & 2.76 & $(0.59)$ \\
\hline \multirow{5}{*}{ Relational } & Short-term & 2.85 & $(0.87)$ & 2.48 & $(0.74)$ \\
\cline { 2 - 6 } & Narrow & 2.76 & $(0.76)$ & 3.03 & $(0.77)$ \\
\hline \multirow{5}{*}{ Balanced } & & 3.27 & $(0.53)$ & 3.79 & $(0.74)$ \\
\hline \multirow{5}{*}{} & Loyalty & 3.48 & $(0.71)$ & 3.55 & $(0.85)$ \\
\cline { 2 - 6 } & Stability & 3.05 & $(0.71)$ & 4.05 & $(0.82)$ \\
\cline { 2 - 6 } & & 3.95 & $(0.51)$ & 3.93 & $(0.71)$ \\
\cline { 2 - 6 } & Performance support & 3.75 & $(0.63)$ & 3.91 & $(0.78)$ \\
\cline { 2 - 6 } & Development & 4.21 & $(0.61)$ & 4.19 & $(0.76)$ \\
\cline { 2 - 6 } & External marketability & 3.89 & $(0.75)$ & 3.69 & $(0.91)$ \\
\hline
\end{tabular}

$* \mathrm{~N}=787$ 
Table 2: Gender differences in employment preferences

\begin{tabular}{|l|l|l|l|l|l|l|l|l|l|}
\hline Gender & \multicolumn{4}{|c|}{ Company size } & \multicolumn{2}{c|}{ Sector } & \multicolumn{2}{c|}{$\begin{array}{c}\text { Entrepreneurial } \\
\text { orientation }\end{array}$} & \multicolumn{2}{c|}{ Type of job } \\
\hline & Small & Medium & Large & Public & Private & $\begin{array}{l}\text { Someone } \\
\text { else's }\end{array}$ & $\begin{array}{l}\text { Self- } \\
\text { employed }\end{array}$ & Expert & Managerial \\
\hline Male & $24 \%$ & $46 \%$ & $30 \%$ & $34 \%$ & $66 \%$ & $45 \%$ & $55 \%$ & $51 \%$ & $49 \%$ \\
\hline Female & $20 \%$ & $52 \%$ & $28 \%$ & $29 \%$ & $71 \%$ & $44 \%$ & $56 \%$ & $49 \%$ & $51 \%$ \\
\hline
\end{tabular}


Table 3: Results of cluster analysis

\begin{tabular}{|l|l|l|}
\hline Preference \& Type of APC & $\begin{array}{l}\text { Cluster 1 } \\
\text { (CEE) }\end{array}$ & $\begin{array}{l}\text { Cluster 2 } \\
\text { (EA) }\end{array}$ \\
\hline Prefer to work in private sector (in \%) & 97.4 & 55.3 \\
\hline Ideal career type (as \% of all career types) & Managerial (64.8) & Expert (64.2) \\
\hline Prefer to have entrepreneurial career (in \%) & 69.1 & 58.6 \\
\hline Preferred company size (as \% of all firms) & Medium (58.4) & Medium (40.9) \\
\hline Relational (employer) (scale: 1-5)* & Below average (3.56) & Above average (4.03) \\
\hline Balanced (employer) (scale:1-5)** & Below average (3.80) & Average (4.06) \\
\hline Transactional (employer) (scale:1-5)*** & Average (2.75) & Above average (2.76) \\
\hline
\end{tabular}

Note: *mean equals to $3.80, * *$ mean equals to 3.93 , ***mean equals to 2.76 . 
Table 4: Comparing HR managers' and students' expectations regarding employee and employer obligations

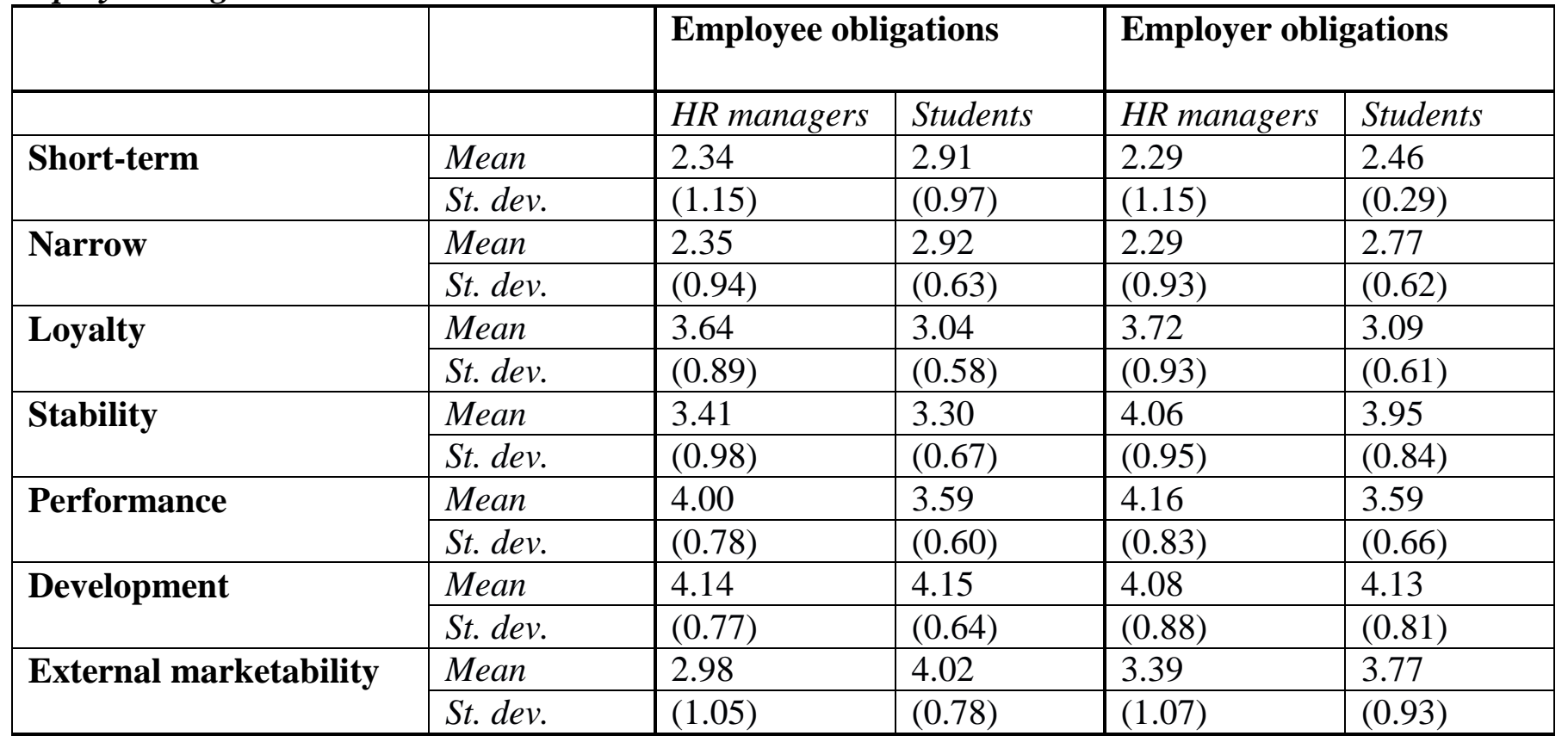


Figure 1: Items with the largest difference between what students expect from employers and what employers offer

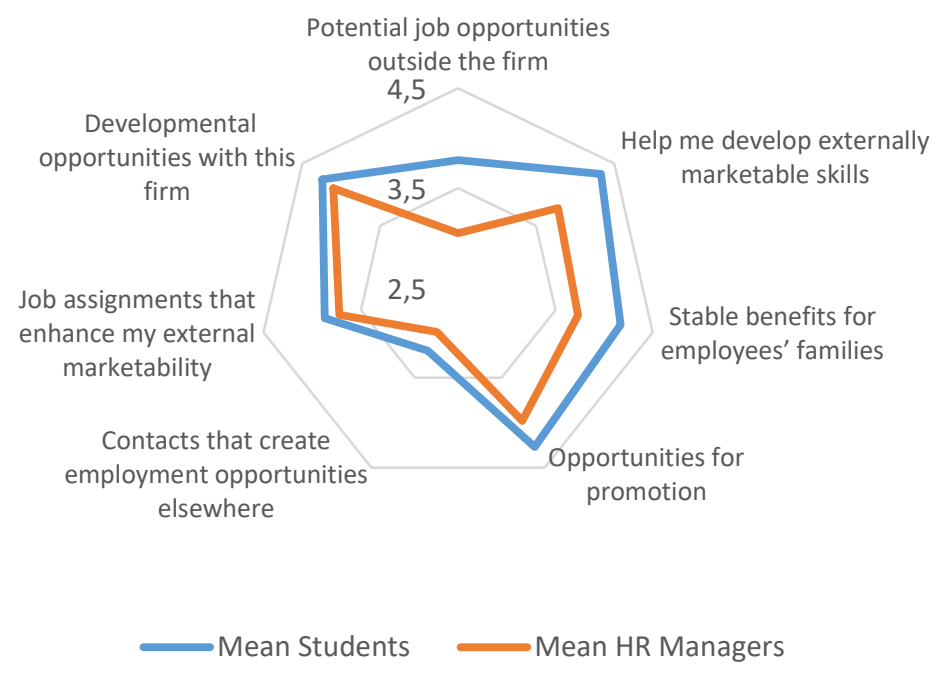

